Presidential Address*

\title{
Realising the future we want for all our children
}

\section{Ramya de Silva ${ }^{1}$}

Sri Lanka Journal of Child Health, 2015; 44(4): 186-192

(Key words: Children, future)

Our Chief Guest Mr. Kumar Sangakkara, Guest of Honour Dr. Palitha Mahipala, Chairperson and Members of the Board of Trustees of the Sri Lanka College of Paediatricians (SLCP), Past Presidents, Members of the Council, Fellows and Members of the SLCP, Past Presidents of the Sri Lanka Paediatric Association, Mr. Faizal Casim, Deputy Minister of Health and other distinguished guests from the Ministry of Health, representatives from the World Health Organisation (WHO), the United Nations Children's Fund (UNICEF) and the World Bank, my teachers, colleagues and friends. It is indeed a great honour and a singular privilege today, to stand before this august audience, on this significant and solemn occasion, as the new President of the SLCP for the year 2015/2016.

This is truly a moment to be valued and cherished. I accept this appointment joyfully but with humility. In the coming year, I will try my very best to give my finest efforts towards making you happy about selecting me. With the blessings of the Triple Gem and with the help of my able Council, together with the fullest cooperation from all of you, I will devote my time and self to carry out the obligations and duties of this prestigious post. Indeed, I am quite sure that jointly, we can achieve our objective of providing better and optimal healthcare to all the children of our land.

I thank the outgoing President, Professor Sujeewa Amarasena, and his Council, for the excellent and admirable work undertaken during the last year. You have just listened to the fantastic work they have carried out under his able guidance. Professor Sujeewa Amarasena, on behalf of The SLCP, I now have the greatest pleasure in presenting you with this Past President's Medal as a very small token of appreciation for all that you have successfully

\section{${ }^{1}$ Consultant Paediatrician, Lady Ridgeway \\ Hospital for Children, Colombo \\ *Address given on induction as President SLCP, October 2015}

The author declares that there are no conflicts of interest.

Open Access Article published under the Creative Commons

Licence. achieved during your tenure of office. In the same vein, it should be recorded here that all the Past Presidents of the College have made very valuable contributions to improving the care of children during their tenures. The College is what it is today because of the commitment and vision of all those wonderful people. I will try my very best to continue with the good work my predecessors have initiated. That is indeed my commitment to you today.

I thank our Chief Guest Mr. Kumar Sangakkara, past Captain of the Sri Lankan Cricket team, a person greatly honoured and loved by Sri Lankans, for ever so readily agreeing to join us today. Thank you Kumar, for taking time off from your very busy schedule to be with us on this memorable evening. I also thank you for that excellent speech and for those kind words. Thank you Yehalie and little Swyree and Kavith, for gracing this occasion.

Dr. Palitha Mahipala, the Director General of Health Services and our Guest of Honour, thank you very much sir, for being with us on this very special evening. Thank you very much for those stimulating words. You have been a source of strength and encouragement to all of us working for the Ministry of Health. Whenever we wanted to meet you, not only did you give us an appointment but also a patient hearing and in the end, provided invaluable advice.

Ladies and gentleman, 'Realising the future we want for all' is the theme for the year 2015/2016. The United Nations heralded the new millennium with the declaration of the Millennium Development Goals (MDGs) that targeted developments in human welfare across the globe in the period up to 2015. The time has come to go beyond the MDGs. We are heading for the next phase, Sustainable Development Goals. The United Nations system is now proclaiming the slogan 'Realising the future we want for all' which goes beyond mere numbers to focusing on equity, inclusiveness and quality ${ }^{1}$. As for the paediatric community, our declared goal should be a refinement of the WHO initiative. I would like to call it 'Realising the future we want for all our children'. 
As the College of Paediatricians, we have chosen this same theme, to guide us in our endeavours for the year 2015/2016. However, we have also decided to broaden the scope, and to specifically address the issues related to neonates, and two other special groups, differently abled children and adolescents. 'Realizing the future we want for all our children', will be addressed at 3 important stages of life, to deliver the vision of the College of Paediatricians during my tenure as President 2015 / 2016. The three stages that would be targeted are:

I. Neonate: Improving neonatal survival

II. Childhood: Identifying disabilities early and enhancing the care of differently abled children

III. Adolescence: Realising the health and wellbeing of adolescents

\section{IMPROVING NEONATAL SURVIVAL}

Ladies and gentlemen, when I became the President-elect of the SLCP, my colleagues told me that I should come to the College leaving behind, what I have always called, "my baby", the newborn. They implied that I have already spent enough time with that 'baby' as the President of the Perinatal Society. Do you think it is fair for me to leave my baby and come? I do not think you will say yes because newborn deaths constitute $64 \%$ of infant deaths and $55 \%$ of under 5 year deaths. Without reducing neonatal deaths we cannot reduce either infant deaths or the under 5 deaths. In such a context, I think this is the most appropriate time to talk about the newborn. I am stressing the point that this is the best time and the best place to talk about the newborn.

I would like to draw your attention to the MDG 4 as we are coming to the end of 2015 . It says by 2015, reduce the 1990 mortality figure for under 5 mortality by two thirds ${ }^{2}$. Have we been able to do this? No, though we say we are on track ... there are only 2 more months to go. Do we have to feel bad about it? Not at all. Why not? Well, we all know and we are proud of the fact that we have the best health indices in the South Asian Region. Our statistics for neonatal, infant and under five mortality are closer to those of upper middle income countries than low middle income countries. In fact, we are closer to the developed nations in that respect. Also, we all know and have seen, what has been happening in the developed countries: that is, when neonatal mortality is low, further reduction is a real uphill task. Is that $a$ reason to relax and wait? No. Why do you think that neonatal deaths are not coming down? Have we not done much for them? No, actually we have done quite a lot over the past two decades. We have improved the infrastructure. Now we have 31 neonatal intensive care units (NICUs). We have 7 neonatologists and 24 paediatricians dedicated to the care of neonates. We regularly use surfactant now. We have more ventilators. We have more Continuous Positive Airway Pressure (CPAP) machines. We have more monitors. So then why is neonatal mortality not coming down in the way we want it to? Ladies and gentlemen, this is why, as a paediatrician and as a neonatologist, I have to take my 'newborn baby' with me to the College of Paediatricians and nurture it, until such time, the baby reaches adolescence, passing a healthy and happy childhood.

It was Confucius, the Chinese Philosopher, who proclaimed "Study the past if you would define the future". The past is very important; it teaches us many a lesson. I would now like to go back in time to 2012. I was speaking at the Neonatal Symposium at the Annual Scientific Congress of the SLCP. The topic was Achieving and going beyond MDG 4: Priorities in newborn care: the role of the neonatologist. I said "neonatal deaths are unique, in a way invisible; all over the world, millions of babies die during the first four weeks of life. Yet, very few, hardly anyone really, talks about them. They do not get the attention of the media nor do they get the attention of the policy makers or the politicians. Neonates do not have a voice, literally and metaphorically. They have only a feeble cry. That is also not loud enough to be heard by others. So, as neonatologists, we have to speak on their behalf'. Ladies and gentlemen, now, I am happy, in fact I am very happy, that the policy makers are now making a big noise, and they are crying aloud, on behalf of these little neonates, demanding that their survival be ensured. I am so happy that in the World Bank press release on $9^{\text {th }}$ of September 2015, quotes UNICEF Deputy Executive Director as saying "far too large numbers of children are still dying from preventable causes before their fifth birthday and indeed within their first month of life. That should compel us to re-double our efforts to do what we know, needs to be done. We cannot continue to fail them".

Colleagues and friends, one crucial omission in global health research and policy has been the health of newborns. While the infant and the mother have been at the centre of efforts to protect early childhood health, the newborn period has been relatively neglected. Newborn deaths account for $44 \%$ of under- 5 year deaths globally ${ }^{4}$. Newborn survival and health were not specifically addressed in the MDG 4. Therefore it received less attention and investment. Newborn mortality requires greater visibility if the overall under-5 mortality rate is to be reduced. 
What are the causes of death in the newborn? There are 4 main contributory factors. More than two thirds of all newborn deaths result from three preventable and treatable conditions. They are prematurity, birth asphyxia and sepsis ${ }^{5}$. The fourth one is congenital anomalies. Out of the neonatal deaths nearly $50 \%$ of the deaths occur within the first 24 hours of birth and $75 \%$ occur in the first week of life ${ }^{5}$.

Over the years, Sri Lanka has had very impressive neonatal, infant and under five year health indices. This was mainly due to more than six decades of free universal health care and free education. Neonatal mortality rate is only 6 per 1000 live births despite having a per capita income of just 3170 USD in $2013^{6}$. However, there has been some concern as the decline in neonatal mortality has been very slow over the past decade, despite the deaths due to birth asphyxia and sepsis being reduced remarkably. Each year, preterm births are increasing in number. Providing care for the preterm is not just for survival. Implications of being born preterm extend beyond the neonatal period and throughout life. Many survivors of prematurity face a lifetime of disability, including cerebral palsy, learning disabilities, chronic lung disease and visual and hearing impairment. The global action report on preterm birth, "Born Too Soon", says that three fourths of neonatal deaths can be prevented, simply by providing the essential newborn care facilities ${ }^{7}$. To reduce the other one fourth of the preterm deaths, one needs neonatal intensive care facilities. This is very true. Sri Lanka has achieved a remarkable reduction in neonatal mortality over the past several decades simply by providing essential newborn care facilities. It is imperative, that we fine tune our national programme on newborn care with special attention to NICUs, if we are to reduce the neonatal mortality further. Unless we reduce neonatal mortality we will not be able to bring down the infant or under five year mortality

How can we fine tune neonatal care? The main areas for intervention are

- Strengthen the neonatal transport service

- Training, development and enhancement of staff skills

- Monitoring and auditing

Strengthening of the neonatal transport service In Sri Lanka $98.6 \%$ of deliveries take place in an institution where skilled birth attendants are available $^{8}$. There are 74 such institutions in the country. However we have only 31 NICUs. When there is a preterm or a sick newborn that needs intensive care, the baby has to be transferred to an NICU where there are such facilities Valuable time is lost in the process. Often the transport is done using a routine ambulance service accompanied by a person, untrained in the care of a critically ill newborn, in vehicles that are not equipped to transfer preterm and sick newborns. Our unit at the Lady Ridgeway Hospital (LRH) had received several babies who had died on the way, due to dislodged or displaced endotracheal tubes or having developed pneumothoraces. Most of the babies that are transferred reach the destination in a very poor condition: in point of fact, with low temperatures, low blood sugars and low oxygen levels. If these problems are not treated then and there, they can lead to death. Even in the event of survival, these can and do lead to permanent physical or developmental disabilities.

The most important concept of neonatal transfer is to mimic an environment of a neonatal intensive care unit, while the baby is being transferred to the centre. The staff travelling in the ambulances designated for neonatal transfer, including the drivers, are specially trained to care for these preterm and sick babies. Prior to transfer the transport team spends time stabilizing the sick baby's condition, to prevent clinical deterioration en route. A dedicated neonatal transport service for the newborns should be available 24 hours a day, 365 days, each and every year. I was able to initiate a neonatal transport service as a pilot project at LRH in 2013 when I was the President of the Perinatal Society ${ }^{9}$ I take this opportunity to thank the team headed by Dr. Amit Gupta, Consultant Neonatologist, John Radcliffe Hospital and Associate Dean, Oxford Deanery, UK for his personal and dedicated efforts to establish the neonatal transport service in Sri Lanka. Without his commitments the project would not have seen the light of day. Dr. Anoma Jayathilake at WHO, Dr. Deepika Attygalle at UNICEF, Dr. Dhammica Rowel at Family Health Bureau (FHB) and Dr. Ratnasiri Hewage, Director, LRH, supported the initiative in a big way. My special thanks go to my staff, the medical and nursing officers who carried out the retrievals. It has now been named a National Service and is being rolled out to the rest of the country. Dr. Mahipala, our Director General gave us all the encouragement to carry on when we were facing many obstacles. Thank you, sir. I am proud to say that this is the very first neonatal transport service in South Asia implemented at a national level. Colleagues and friends, an efficient neonatal transport service is mandatory for reduction in neonatal mortality and morbidity. Unless the preterm and the sick neonates are transferred in the best possible and optimal condition to the centre, the chances of survival are very poor, despite providing the most laudable intensive care. Even for those who survive, it will be at a cost, with permanent disabilities. My Council and the Neonatal Transport Forum of the 
SLCP, will support and strengthen the neonatal transport service to reduce neonatal deaths and to improve the quality of survival. The Team from the UK will be here again in February 2016 to do the second phase of 'Training of Trainers' course. There will be 2 workshops, in Jaffna and Polonnaruwa to cover the North, North Central and North Western provinces. I am delighted to announce that we will be training paediatricians from 5 SARRC countries under South-South Cooperation at this workshop. I am very grateful to Dr. Deepika Attygalle at UNICEF for sponsoring the whole project.

Training, development and enhancement of staff skills

Sir Liam Donaldson, Chief Medical Officer of England, states in his 2009 Annual Report ${ }^{10}$, 'When a person steps on a plane, the risk of dying in an air crash is 1 in 10 million. When a person is admitted into a hospital, the risk of dying or being seriously harmed by a medical error is 1 in 300". Amongst a number of recommendations to the UK government, he urged that 'Simulation training in all its forms will be a vital part of building a safer healthcare system'. Ladies and gentlemen, Gone are the days where doctors were considered Gods. Currently, there is a growing awareness among people about medical errors. It is no longer acceptable to practise procedures and manage clinical events for the very first time on real patients. Patient safety is one of the most compelling reasons to embrace simulation into healthcare training. Dr. David Grant, the Assistant Officer in Charge of 'Simulation' of the Royal College of Paediatrics and Child Health of the UK will facilitate two 'Training of Trainers' workshops in Colombo and Kandy. The plan is to train 48 paediatricians and nurses. The vision is to have a simulation training centre for each province. Our mission would be to catalyse the process. UNICEF has pledged to support the programme for two years. I thank Dr. Renuka Jayatissa, Nutrition Specialist, UNICEF, for all the help given. Interventions like the neonatal transport service and 'Simulation and Technology Enhanced Learning' incorporated into the National Programmes will directly improve the quality of care provided to the preterm and the sick neonate. These services will have a positive impact towards further reducing neonatal mortality. We will continue to support the on-going activities to reduce neonatal deaths such as neonatal life support (NLS) and advanced paediatric life support (APLS) courses. Thanks to the dedicated commitment by Dr. Srilal de Silva, and as a direct result of the NLS programmes, deaths due to birth asphyxia have been reduced significantly over the past several years. Regarding Essential Newborn Care Training, my Council members representing the Provinces will strengthen the service by conducting training regularly at provincial level. Regarding Care of the Sick Newborn Training, we hope to conduct these courses for all levels of staff that care for the neonate on a regular basis. Regarding Pulse Oximetry Screening to Detect Congenital Heart Disease, what Professor Sujeewa Amarasena introduced in July, we will propagate and support, to make sure that every newborn is screened for congenital heart disease.

Enhancing systems and procedures through monitoring and auditing

It is crucial that we have proper data collection and regular audits. Such data can be used to monitor progress and adjust programme implementation nationally. Over the years we have focused on quantity, increasing survival rates. Now it is time to focus on the quality of what we are delivering as well. In that perspective, we have to survey not only coverage but the quality of the services provided and also assess how they relate to parent satisfaction.

\section{IDENTIFYING DISABILITIES EARLY AND ENHANCING CARE OF DIFFERENTLY ABLED CHILDREN}

This is another area I would like to address during my tenure as the President of the College. Like the newborn, differently abled children have not got sufficient attention from healthcare policy makers. Sri Lanka has an Under 5 population of about 1.77 million $^{11}$. Out of this 10 to $20 \%$ of children have some form of disability that requires special care ${ }^{12}$. This means over 266,000 under 5 children in the country need special needs care services at any given time. Disability is defined... as any restriction or lack of ability to perform an activity in the manner or within the range considered normal ${ }^{13}$. It may be some impairment, limitation of activities or restrictions in participation. Developmental surveillance is the best method to detect delays and impairments. These are performed by skilled and knowledgeable professionals. It is a flexible and a continuous process where a child's development is assessed in the context of overall wellbeing in a longitudinal process. It is very important that children with developmental delays are identified as early as possible to commence timely interventions with family involvement, aimed at preventing delays and creating a more stimulating and protective environment. At-risk groups should be identified at birth itself. It is imperative that all the babies who have been discharged from NICUs be regularly assessed to detect any impairment as early as possible. This is very important as more and more at risk babies survive with improved neonatal care. In addition all children should have regular 
systematic developmental monitoring through their childhood. Those children who are identified as having delays or impairments should be referred for early interventions. Early interventions prior to 3 years have proven to result in better outcomes for children with cerebral palsy, autism and intellectual disabilities ${ }^{14}$. During my tenure of office, we will sensitize the health care workers providing care for the preterm and sick neonates about the burden of disability, stress the importance of early detection and referring for therapy and advocate for at risk babies to be monitored at special clinics under the supervision of a Community Paediatrician. We will also encourage establishment of community based child development centres and data collection and regular audit and finally advocate for parent support groups. Friends, we have made arrangements to conduct a disability care workshop by a highly trained and very well experienced team from London in May 2016. The team will conduct 2 workshops in Colombo and Kandy. These activities, ladies and gentlemen, will definitely improve the quality of survival of our babies who have braved the storms at birth.

\section{REALISING THE HEALTH AND WELLBEING OF ADOLESCENTS}

Ladies and gentlemen, realising the health and wellbeing of adolescents is the caption of an article that appeared in the British Medical Journal published on the $14^{\text {th }}$ September $2015^{15}$. Like the newborn, the adolescent was also marginalized. Yet again I am glad that they now say "Investing in adolescents' health and development is key to improving their survival and wellbeing and critical for the success of the post-2015 development agenda. Sri Lanka has 3.35 million adolescents (1019 years) comprising $16 \%$ of the total population ${ }^{11}$. Of them $69 \%$ are still attending school $^{16}$. Adolescence is one of the most dynamic stages of human development. Generally it is characterized by good health. It's a time when dramatic physical, cognitive, social and emotional changes take place. Because of the rapid development occurring during this period, many physical and mental health conditions, substance use disorders and health risk behaviours emerge for the first time. Providing care to adolescents can be challenging. They often struggle to make decisions on their own; they need guidance. However, they may be unwilling to acknowledge that need. Confidentiality protection is an essential component of healthcare for adolescents. They will be reluctant to seek advice if that is not there. Regular preventive-care visits by the school medical officers will provide opportunities for early identification of problems. Appropriate management and effective interventions have to be carried out for conditions and behaviours that can become serious problems and persist into adulthood. To deliver effective health interventions to adolescents, availability of good quality care and healthcare workers trained to deal with adolescents is critical. Efforts to improve adolescent health require health systems that are responsive to adolescents. Stigma, discrimination, judgmental treatment, lack of confidentiality, and inability to physically access services have been shown to be important barriers to care ${ }^{15}$. Evidence from both high and low income countries shows that services for adolescents are highly fragmented, poorly coordinated, and uneven in quality. Outreach and non-facility based services are important to reach adolescents who otherwise will not access such services. Variability in quality can be minimised by setting standards and supporting their achievement. How can we help the adolescents? We are going to establish an Adolescent Forum within the Sri Lanka College of Paediatricians to address the vital issues of adolescents. Our main aim is to create health systems that are suited to the adolescents. We will facilitate training of mentors and volunteers to develop meaningful and sustained relationships with adolescents and to do counselling when necessary within the school set up. Advocacy to establish outreach and non-facility based services, under the supervision of Consultant Community Paediatricians and to create Adolescent Wards in hospitals will be done. The young are dynamic, have powers of creativity and involvement that can contribute greatly to the betterment of society. Ensuring that the youth in our country are physically and mentally strong and emotionally secure will undoubtedly ensure not only economic growth but social development as well. The Adolescent Forum we are going to form within the SLCP will help in this endeavour. We have already had discussions with the Royal College of Paediatrics and Child Health of the UK for advocacy to improve the care provided to our adolescents. We have planned to conduct a Training-of-Trainers' course for the healthcare workers providing care for the adolescents in June 2016. I am very thankful to Professor Neena Modi, President of the Royal College of Paediatrics and Child Health for all the support extended in this regard.

Ladies and gentlemen, I decided to take up the Presidency of the College of Paediatricians, to underscore the need for all of us to work together to ensure that my neonate survives; that this baby is given all the necessary care, throughout his or her childhood. This would include early detection of any delays and impairments together with rapid and appropriate action being taken to redress the balance. Then at the age of five the little child, whether abled or differently abled, will begin a new phase; a phase when their lives will be 
enriched by education, and will grow and develop. We will then ensure that the challenges they face, as they grapple with growing responsibilities, complex interactions and changing physical appearances are supported, and strengthened. It is our fervent wish to see them sail through turbulent adolescence unruffled, and grow up to be healthy and productive young adults that we could all be proud of. Indeed, if we can set the foundation for such a journey in this one year, we would rest, assured that all of us have contributed meaningfully to our objective: 'Realising the future we want for all our children'. Today, this is our pledge to the children of our country

\section{Acknowledgements}

I need to respectfully acknowledge all those people who have played a pivotal role in my life. First and foremost, my late Amma and Thaththa, I wish that both of you were here today. I have no words to express the deep appreciation I have for all that you have done for me. Thank you Amma and Thaththa. I thank all my teachers. They played a very significant role in my life. I am so glad that my favourite teacher, Mrs. Kodagoda who was my $\mathrm{A} /$ Level class teacher and Botany teacher is here today. Thank you madam. My teachers in the Faculty of Medicine, in the Extended Faculty of the Hospitals, those in the Postgraduate Institute of Medicine, together with the Consultants whom I worked under both here and abroad, all of them were instrumental in shaping my professional life. I am ever so grateful to them. My sisters, brother, close relatives and my friends were always there for me, in good times as well as in bad. Their commitment and affection have meant so very much to me. Thank you. There are 3 special people I would like to express my sincere gratitude to. First of all to Dr. BJC Perera, the very first President of the Sri Lanka College of Paediatricians, Sir, thank you very much for your expert advice and comments which were given ever so readily whenever I sought them and also for being an inspiration to me as I take up this post. Professor Amala de Silva, my dear sister in law and Dr. Amit Gupta, my good friend. I am so grateful and thankful to both of you for giving me all the assistance, strength and encouragement. Finally, my own family. I am ever so grateful to my husband Sanath, our children Chathuri and Bhathiya for being just what they are. The unconditional love showered on me by all three of them has always been an inspiration for my life. I am so lucky and am so very grateful to all three of them for sharing my life and being there for me. As I stand here today, I do acknowledge that all my achievements, are theirs as well. Ladies and Gentlemen, I am deeply moved by your presence here today. No one could ask for more. I thank you, from the bottom of my heart. Please do enjoy the rest of the evening.

\section{References}

1. United Nations Development Programme. Realising the future we want for all. Available from:

http://www.undp.org/content/undp/en/hom e/librarypage/poverty-reduction/realizingthe-future-we-want.html

2. World Health Organisation. MDG 4: Reduce child mortality. Target 4A: Reduce by two-thirds, between 1990 and 2015, the under-five mortality rate. Available from:

http://www.who.int/topics/millennium_de velopment_goals/child_mortality/en/

3. De Silva R. Achieving and going beyond MDG4-Priorities in Newborn Care: Role of the neonatologist. Proceedings of the Sri Lanka College of Paediatricians $15^{\text {th }}$ Annual Scientific Congress 2012; 4(1): 50.

4. Liu L, Oza S, Hogan D, Perin J, Rudan I, Lawn JE, et al. Global, regional, and national causes of child mortality in 2000 13, with projections to inform post- 2015 priorities: an updated systematic analysis. Lancet 2015; 385: 430-40.

http://dx.doi.org/10.1016/S01406736(14)6 1698-6

5. Newborn death and illness. Updated September 2011. Available from: http://www.who.int/pmnch/media/press_m aterials/fs/fs_newborndealth_illness/en/

6. World Development Indicators 2015, World Bank Database, World Bank. Available from:

http://data.worldbank.org/datacatalog/worl d-development-indicators

7. Born Too Soon: The Global Action Report on Preterm Birth. 2012. Available from: http://www.who.int/pmnch/media/news/20 12/201204_borntoosoon-report.pdf

8. Childbirth in Sri Lanka. From Wikepedia, the free encyclopaedia. Available from: https://en.wikipedia.org/wiki/Childbirth_i n_Sri_Lanka\#Location_and_type_of_de-ii very 
9. Neonatal Transport Service - Lady Ridgeway Hospital for Children. Available from: http://slcp.lk/?p=3866

10. 2009 Annual Report of the Chief Medical Officer of England. Available from: http://www.sthc.co.uk/Documents/CMO Report_2009.pdf

11. Department of Census and Statistics: Revised mid-year population estimates by age group and sex 2012-2014. Available from:

http://www.statistics.gov.lk/PopHouSat/Vi talStatistics/MidYearPopulation/Midyear $\% 20$ population $\% 20$ by\%20age\%20group.p df

12. van Dyck PC, Kogan MD, McPherson MG, Weissman GR, Newacheck PW. Prevalence \& characteristics of children with special health care needs. Archives of Pediatric and Adolescent Medicine 2004; 158(9):884-90.

http://dx.doi.org/10.1001/archpedi.158.9.8 84

PMid: 15351754

13. The United Nations and Disabled Persons: The first fifty years. Available from: http://www.un.org/esa/socdev/enable/dis5 0y10.htm
14. The Royal Australasian College of Physicians Paediatric \& Child Health Division. Position Statement. Early intervention for children with developmental disabilities. August 2013 Available from: file://C:/Users/User/Downloads/EarlyInte rventionAugust2013.pdf

15. Laski L. Realising the health and wellbeing of adolescents. British Medical Journal 2015; 351: h4119. Available from:

http://www.bmj.com/content/351/bmj.h41 19

http://dx.doi.org/10.1136/bmj.h4119 PMid: 26371214

16. Ministry of Education, "Sri Lanka Education Information 2013" http://www.moe.gov.lk/english/index.php? option $=$ com content $\&$ view $=$ article $\& i d=12$ 20\&Itemid $=922$ 